Oikos 118: 529-538, 2009

doi: $10.1111 /$ j.1600-0706.2009.17283.x,

(C) 2009 The Authors. Journal compilation (C) 2009 Oikos

Subject Editor: Pia Mutikainen. Accepted 31 October 2008

\title{
Germination responses of an invasive species in native and non-native ranges
}

\author{
José L. Hierro, Özkan Eren, Liana Khetsuriani, Alecu Diaconu, Katalin Török, Daniel Montesinos, \\ Krikor Andonian, David Kikodze, Levan Janoian, Diego Villarreal, María E. Estanga-Mollica and \\ Ragan M. Callaway
}

J. L. Hierro (jhierro@exactas.unlpam.edu.ar) and R. M. Callaway, Div. of Biological Sciences, The Univ. of Montana, Missoula, MT 59812, USA. JLH also at: INCITAP-CONICET and Facultad de Ciencias Exactas y Naturales, Universidad Nacional de La Pamba, AR-6300 Santa Rosa, Argentina-D. Villarreal and M. E. Estanga-Mollica, Facultad de Ciencias Exactas y Naturales, Univ. Nacional de La Pampa, AR-6300 Santa Rosa, Argentina. - Ö. Eren, Adnan Menderes Üniv., Fen-Edebiyat Fakültesi, Biyoloji Bölïmü, TR-09010, Aydin, Turkey. - L. Khetsuriani and D. Kikodze, Inst. of Botany of the Georgian Academy of Sciences, 380007 T'bilisi, Georgia. - A. Diaconu, Inst. of Biological Research, Biological Control Laboratory, RO-700107 Iasi, Romania. - K. Török, Inst. of Ecology and Botany of HAS, HU-2163 Vácrátót, Hungary. - D. Montesinos, Centro de Investigaciones sobre Desertificación, ES-46470 Albal, Spain. - K. Andonian, Ecology and Evolutionary Biology Dept, Univ. of California, Santa Cruz, CA 95064, USA. - L. Janoian, Environmental Conservation and Research Center, American Univ. of Armenia, Yerevan, Armenia.

\begin{abstract}
Studying germination in the native and non-native range of a species can provide unique insights into processes of range expansion and adaptation; however, traits related to germination have rarely been compared between native and nonnative populations. In a series of common garden experiments, we explored whether differences in the seasonality of precipitation, specifically, summer drought vs summer rain, and the amount and variation of annual and seasonal precipitation affect the germination responses of populations of an annual ruderal plant, Centaurea solstitialis, from its native range and from two non-native regions with different climates. We found that seeds from all native populations, irrespective of the precipitation seasonality of the region in which they occurred, and non-native populations from regions with dry summers displayed similarly high germination proportions and rates. In contrast, genotypes from the non-native region with predominantly summer rain exhibited much lower germination fractions and rates. Also, percent germination was strongly correlated with variation in precipitation in winter, the season that follows germination for C. solstitialis. Specifically, germination was lower for native and non-native populations experiencing greater variation in winter precipitation. This correlation, however, was greatly influenced by the non-native region with summer rain, which also exhibited the greatest variation in winter precipitation among studied regions. These results suggest that rather than general climatic patterns, the degree of risk experienced at early developmental stages could exert an important control over the germination strategy of $C$. solstitialis populations in both native and non-native ranges. Also, these findings reveal a largely unique germination response in $C$. solstitialis genotypes growing in the non-native region with summer rain and high variation in winter precipitation. Our work raises the possibility that rapid adaptive changes in germination strategies may contribute to the success of globally distributed invaders.
\end{abstract}

Since the pioneering work of Turesson (1922) and Clausen et al. (1941), understanding genetic differentiation among populations has been pivotal for biogeography, evolution, and ecology. Several reviews have recently emphasized that contemporary biological invasions provide an exceptional context in which to further investigate this subject (Bossdorf et al. 2005, Sax et al. 2007). Organisms transported by humans to regions where they are not native (exotics) commonly face novel selective forces, which given enough genetic variation, may trigger novel evolutionary responses. For exotic plants, and in particular for those introduced with agricultural species, a history of multiple introductions and hybridization among previously allopatric populations appear to provide the required high genetic variation upon which selection might act (Ellstrand and Schierenbeck 2000, Bossdorf et al. 2005, Novak and Mack 2005). Natural selection is the dominant driver of genetic differentiation (Linhart and Grant 1996), and promotes change even in bottlenecked populations (Koskinen et al. 2002), but genetic drift may also operate following the introduction event (Barrett and Husband 1990). Regardless of the mechanism, exotics provide exceptional systems for addressing questions about intraspecific genetic divergence.

Various life history traits have been compared between native and non-native plant populations, but, surprisingly, traits related to germination have been ignored (Bossdorf et al. 2005). This deficiency is remarkable considering that germination life history traits are thought to be under 
particularly strong selection because of their crucial consequences for fitness (Cohen 1966, Venable and Brown 1988, Evans and Cabin 1995, Donohue et al. 2005, Venable 2007). Based on the proportion of seeds germinating in a given year, species and ecotypes have been commonly divided into two broad contrasting germination strategies: a rapid germination of a large proportion of seeds, ostensibly to maximize site pre-emption, versus a strategy in which only a small proportion of seeds germinate and a large proportion remains dormant (Cohen 1966). Seed dormancy has been characterized as a risk-spreading or bet-hedging strategy to avoid unfavourable growing conditions and/or buffer the effects of unpredictable environments (Venable and Brown 1988). Genetic differentiation for seed dormancy among populations has been reported for a number of species (Baskin and Baskin 2001, pp. 190192), including exotics (Naylor 1983, Wu et al. 1987, Meyer and Allen 1999), but to our knowledge no study has compared the germination strategies of populations in both the native and non-native range of a species. Conducting such comparisons can be important for understanding patterns of range expansion and processes of adaptation (Donohue et al. 2005).

Centaurea solstitialis (yellow starthistle, Asteraceae) is an annual ruderal native to western Eurasia that has been introduced into several regions of the world (Maddox et al. 1985). The worldwide distribution of this species encompasses environments with contrasting precipitation regimes within both native and non-native ranges. Specifically, some of the regions where $C$. solstitialis grows are characterized by a Mediterranean-type climate with wet winters and dry summers, whereas other regions have a precipitation regime in which most of the precipitation falls during the summer, and winters are substantially drier. In all regions, the species germinates primarily in autumn (Sheley and Larson 1994, Hierro et al. 2006, L. Khetsuriani, L. Janoian and K. Andonian unpubl.); thus, winter conditions may affect its survival. Accordingly, Joley and colleagues (1997, 2003) have argued that $C$. solstitialis germination is well synchronized to a Mediterranean-type climate. Differences in the seasonality of precipitation may, then, impose divergent selection pressures, which in turn can influence the germination strategy of $C$. solstitialis populations. Additionally, germination responses have been commonly linked to particular characteristics of the precipitation regime, such as the amount and inter-annual variation of seasonal and annual precipitation (Philippi 1993, Clauss and Venable 2000, Venable 2007). In general, higher proportions of germinating seeds are expected to occur in regions with relatively high precipitation and/or low variation in precipitation among years, while the opposite is expected in regions with relatively low precipitation and/or high variation in precipitation (Cohen 1966, Venable and Brown 1988, Venable 2007). Thus, changes in these precipitation variables throughout the distributional range of $C$. solstitialis could also exert control over the germination behavior of its populations.

Here, by conducting a series of common garden experiments in a growth chamber, we investigated whether contrasting differences in the seasonality of precipitation and changes in surrogates for environmental quality (e.g. precipitation totals) and risk (e.g. inter-annual variation in precipitation) affect germination responses of $C$. solstitialis populations occurring across its native range and in two climatically distinct non-native regions.

\section{Material and methods}

\section{Study system}

Centaurea solstitialis is often considered as to be native to southern Europe; however, Prodan (1930, as cited in Maddox et al. 1985) argued that southern Europe was actually invaded by $C$. solstitialis from the eastern Mediterranean and Caucasus regions, which are considered by Prodan to be the original range of the species. The genus Centaurea exhibits its greatest diversity in these regions (Wagenitz 1955, as cited in Maddox et al. 1985), supporting this view. Recent phylogenetic analyses also suggest that $C$. solstitialis originated in the eastern Mediterranean and the Caucasus, and it is thought to be one of the first invaders linked to agriculture (N. García-Jacas, Bot. Inst. of Barcelona, pers. comm.). Because of its presumed long presence in central and southern Europe, we, as most authors, consider these European regions as part of the native range of the species. In the 1800 s, probably as a result of increased intercontinental travel and commerce, C. solstitialis was introduced into California, South America (central Argentina and Chile), Australia and South Africa, most likely as a contaminant of alfalfa seeds (Maddox et al. 1985). Because the presence of $C$. solstitialis in these regions is limited to approximately 150 years, and is clearly due to human cross-continental introductions, we refer to these regions as the non-native range of the species (Bossdorf et al. 2005). This worldwide distribution of $C$. solstitialis provides the context in which we assessed the germination response of populations growing under divergent precipitation regimes within both native and non-native ranges. In the non-native range, we focused our sampling on northern California and La Pampa province in Argentina, regions where C. solstitialis exhibits similarly high density and performance (size and fecundity), in spite of their contrasting biotic and abiotic conditions (Hierro et al. 2006). Although these regions have highly contrasting seasonality of precipitation, mean annual temperatures are virtually identical (Fig. 1, < http://www.worldwideclimate.com $>$ ).

Given the presumed introduction mode of $C$. solstitialis (Maddox et al. 1985), the history of global introductions of this species can be compiled from records of imported alfalfa seeds (Gerlach 1997). These records indicate that C. solstitialis populations in California (Gerlach 1997) and Argentina (Hijano and Basigalup 1995) are each derived from multiple introductions from the old world and from a broad array of similar source populations. California populations appear to be derived from Chile (Spanish origin), France, Italy, Spain and Argentina, whereas populations in Argentina appear to be derived from Chile (Spanish origin), France, Italy and Syria. Probable introduction dates are $\sim 1850$ for California (Gerlach 1997) and $\sim 1870$ for central Argentina.

In all regions, the species forms a rosette during winter, bolts and sends up stalks with floral buds in the spring, flowers and fruits in mid-late summer, and dies by the end 


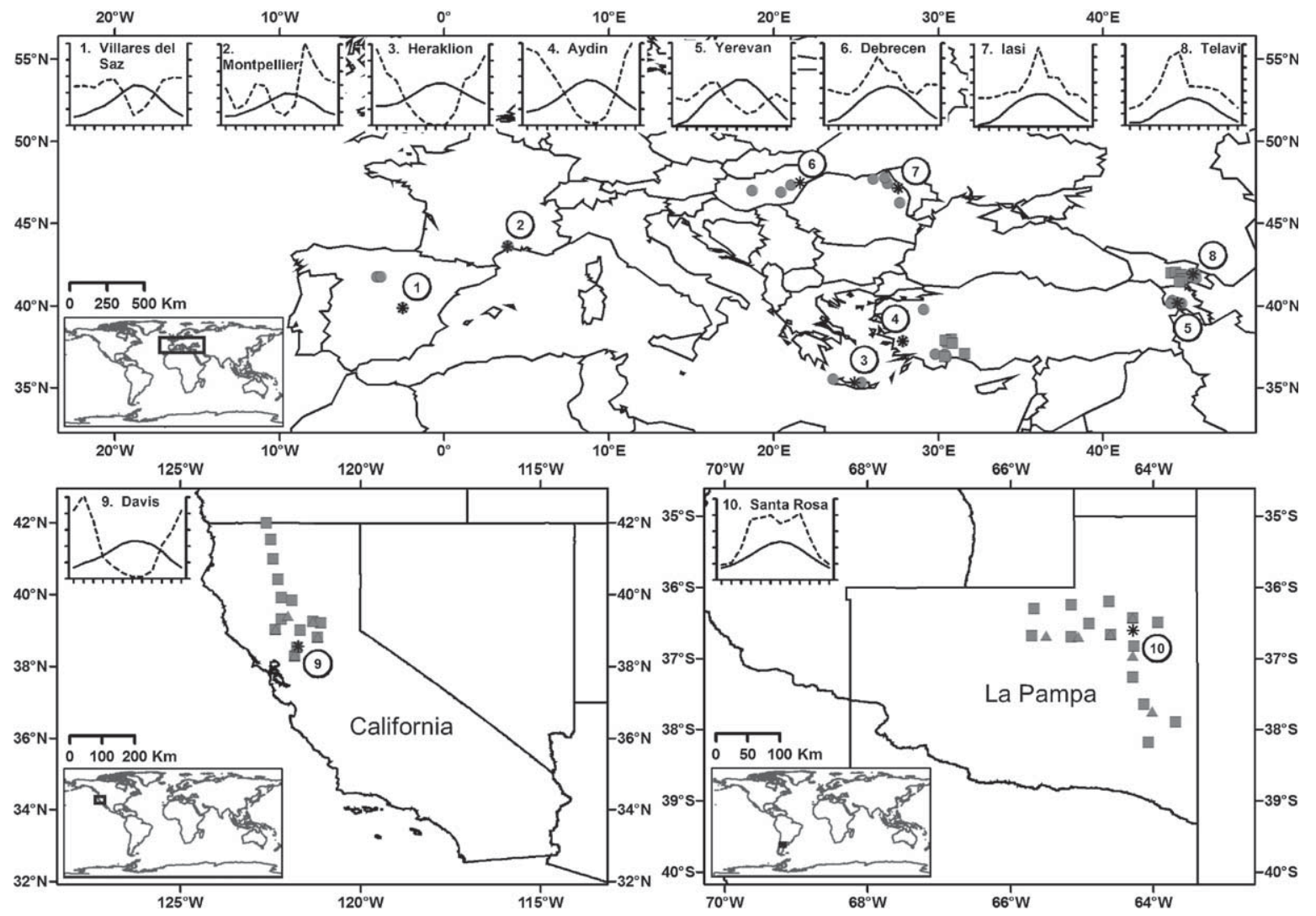

Figure 1. Distribution of native (western Eurasia) and non-native (northern California and La Pampa in central Argentina) C. solstitialis populations from which seeds were collected for this study. Symbols identify populations whose seeds were collected in three different periods and latter used in four common garden experiments; triangles, January (La Pampa) and August (California) 2002 used in Trial 1 and Trial 3; squares, August 2004 (California and Eurasia) and January 2005 (La Pampa) used in Trial 2 and Trial 3, and circles, August 2006 (Eurasia) used in Trial 4. Some populations in the non-native range were re-sampled in the two collections involving this range (see Supplementary material Appendix 1 for coordinates). Asterisks and nearby encircled numbers locate selected cities for which climatic diagrams are displayed (see also Table 1); dashed lines depict precipitation, while solid ones do temperature.

of the same season or in early autumn (Sheley and Larson 1994, Hierro et al. 2006, L. Khetsuriani et al. unpubl.). Flowers are predominantly self-incompatible (Sun and Ritland 1998), and produce achenes (hereafter referred to as seeds) with a pappus and without a pappus in a proportion of approximately 5 to 1, respectively (Benefield et al. 2001). These two seed morphs differ in dispersal time; pappus seeds are dispersed in summer, while non-pappus ones are retained in the capitula and disperse in autumn and winter (Maddox et al. 1996). The species forms persistent seed banks in Turkey (Uygur et al. 2004), Georgia (C. Lortie and J. L. Hierro unpubl.), California (Joley et al. 2003, C. Lortie and J. L. Hierro unpubl.), and central Argentina (C. Lortie and J. L. Hierro unpubl.).

\section{Seed collections}

To investigate the potential effects of seasonality of precipitation on $C$. solstitialis germination, we conducted three successive seed collections from populations occurring in regions with summer drought and summer rain in both the native and non-native range (Fig. 1). In 2002, we collected seeds from six populations in Argentina (January) and six populations in California (August). Seeds were collected from a minimum of 30 individuals per population and then pooled within populations. In this and other collections, seeds were stored in paper bags at room temperature until the initiation of experiments. In 2004 and 2005, we conducted a second collection consisting of 14 populations from California (August 2004), 14 populations from Argentina (January 2005), and 11 populations from what is considered to be the original range of C. solstitialis (August 2004). Within the original range, six populations were in Turkey, a region with summer drought, and five were in Georgia (Caucasus), a region with summer rain (Fig. 1). In all cases, seeds were collected from 30 individuals per population and half-sib seeds were kept in separate envelopes. We conducted a final collection of C. solstitialis seeds in August 2006. This collection encompassed 16 populations growing in regions with summer drought and 13 populations in regions with summer rain climates in western Eurasia. As before, seeds were collected from 30 individuals per population and halfsib seeds were placed in separate envelopes, except for collections in France, Crete and Armenia, where seeds were pooled within populations. Location and elevation of sampled populations are displayed in Supplementary material Appendix 1. 


\section{Common garden experiments}

We conducted a series of common garden studies to assess the possibility that precipitation seasonality affects germination proportions of $C$. solstitialis populations.

\section{Trial 1. Non-native populations}

We began these studies by conducting a common garden experiment in a growth chamber testing for differences in germination strategies between non-native populations of C. solstitialis from California (summer drought) and Argentina (summer rain). This experiment was started in May 2004 using seeds collected in 2002 and included only pappus seeds. In other studies of the germination of C. solstitialis seeds from Californian populations, Joley et al. (1992, 1997, 2003) found that seeds stored in warm $\left(\sim 21^{\circ} \mathrm{C}\right)$ and dry conditions for a minimum of two months germinated in larger proportions and at higher temperatures than freshly collected seeds, suggesting that seeds are conditionally dormant when freshly ripe. Because it is not possible to simultaneously collect seeds of C. solstitialis in the northern and southern hemispheres, we stored seeds at room temperature for a minimum of two months in identical conditions before starting experiments. In all common garden experiments, we only used seeds that looked healthy and filled with an embryo. Such seeds are round and make a distinct sound after hitting a metal tray when released from a few centimeters above the tray; flat seeds and those that did not make an appropriate sound were discarded. Temperature in the chamber was set at $16^{\circ} \mathrm{C}$ to represent conditions during the months in which C. solstitialis commonly germinates (i.e. the mean of the average temperature for Davis, California, in October is $17^{\circ} \mathrm{C}$ and the average temperature for Santa Rosa, La Pampa, in April is $15^{\circ} \mathrm{C}$ ). In addition, the chamber was set at a light:dark cycle of 12:12 hours. Photosynthetically active radiation reaching the seeds was $287 \mu \mathrm{mol} \mathrm{m}^{-2} \mathrm{~s}^{-1}$, as measured with a light meter. The same growth chamber and settings were used in all experiments reported here. Seeds were germinated in nine-cm diameter petri dishes containing $3.0 \mathrm{~g}$ of sterilized cotton, a filter paper placed on top of the cotton, and $50 \mathrm{ml}$ of distilled water. After 16 days, we added an extra $10 \mathrm{ml}$ of water to each petri dish to keep the seeds wet. We used 90 seeds per population, divided among three petri dishes (30 seeds each), which were placed randomly inside the growth chamber and rotated regularly throughout the duration of the experiment. Seeds were considered germinated after the radicle emerged, and seeds were removed from petri dishes immediately after germination. We assessed germination daily for a week and then at larger intervals for a total of 38 days (Fig. 2A). To determine whether ungerminated seeds at the end of the experiment were dormant or dead, we conducted the tetrazolium test (Cottrell 1947). In all experiments, we measured cumulative percent germination at the end of the experiment, expressed as percentage of total viable seeds (Meyer and Allen 1999), and rate of germination, as determined by Timson's index $\Sigma \mathrm{n}$, where n is the cumulative daily germination percentage for each day of the study (Timson 1965, Baskin and Baskin 2001).
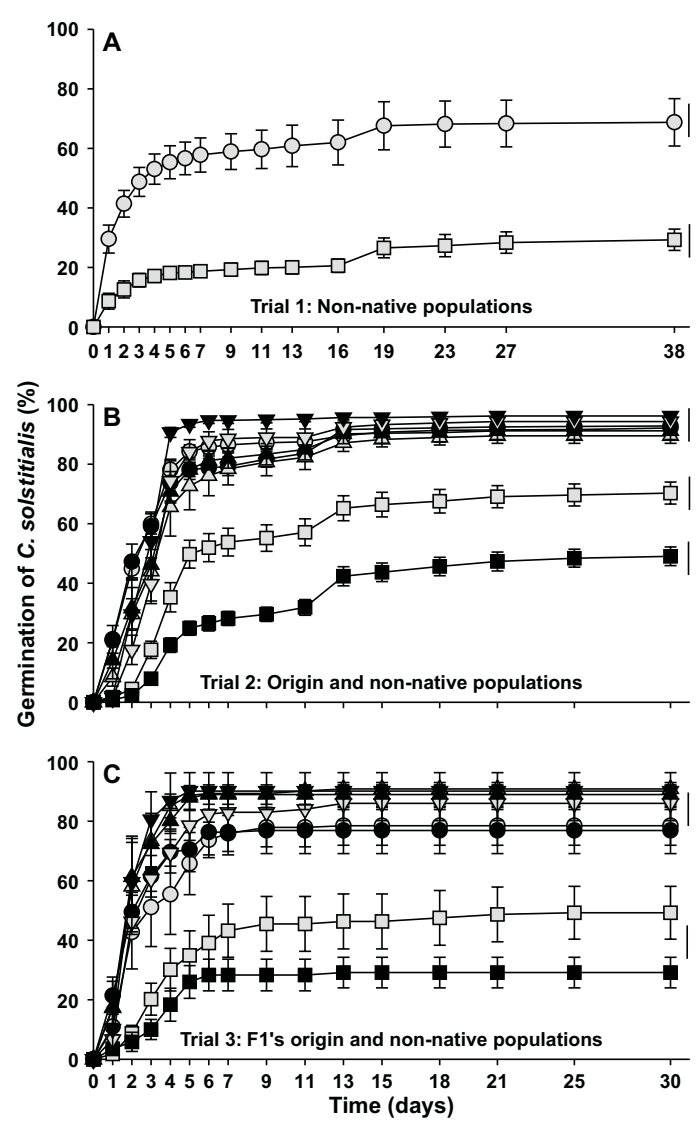

Figure 2. Germination of C. solstitialis pappus (gray symbols) and non-pappus (black symbols) seeds from populations experiencing summer drought and summer rain climates within original and non-native ranges. Symbols are means \pm 1 SE of populations from California (circles), central Argentina (squares), Turkey (triangles up) and Georgia (triangles down). Lines next to germination curves separate statistically different final cumulative germinations $(p<0.05)$. (A) germination of pappus seeds from non-native populations in California (summer drought, $\mathrm{n}=6$ ) and central Argentina (summer rain, $\mathrm{n}=6$ ). Cumulative percent germination, $\mathrm{F}_{\text {seed origin }(1,10)}=20.45, \mathrm{p}=0.001, \mathrm{~F}_{\text {population(seed origin) }(10,24)}=$ $6.00, \mathrm{p}<0.001$; rate of germination, $\mathrm{F}_{\text {seed origin }}(1,10)=38.64$,

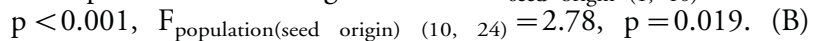
germination of pappus and non-pappus seeds from origin populations in Turkey (summer drought, $n=6$ ) and Georgia (summer rain, $\mathrm{n}=5$ ) and non-native populations in California $(\mathrm{n}=14)$ and central Argentina $(\mathrm{n}=14)$. Cumulative germination, $\mathrm{F}_{\text {seed origin }(3,35)}=70.35, \mathrm{p}<0.001, \mathrm{~F}_{\text {seed type }(1,191)}=1.61, \mathrm{p}=$ $0.207, \quad \mathrm{~F}_{\text {population(seed origin) }}(35,191)=1.97, \mathrm{p}=0.002, \mathrm{~F}_{\text {seed }}$ origin $\times_{\text {seed type }}(3,191)=11.14, \mathrm{p}<0.001$; rate of germination, $\mathrm{F}_{\text {seed origin }(3,35)}=79.69, \mathrm{p}<0.001, \mathrm{~F}_{\text {seed type }(1,191)}=2.73, \mathrm{p}=$

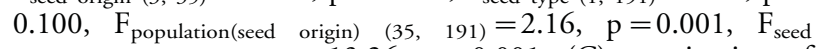
origin $\times_{\text {seed type }}(3,191)=13.26, p<0.001$. (C) germination of seeds obtained from C. solstitialis plants from Turkey (five of the six populations used in Fig. 2B), Georgia (same populations as in Fig. 2B), California (same populations as in Fig. 2A), and Argentina (same populations as in Fig. 2A) grown under common conditions (i.e. evaluation of maternal effects). Cumulative germination, $\mathrm{F}_{\text {seed origin }(3,21.42)}=17.05, \mathrm{p}<0.001, \mathrm{~F}_{\text {seed type }}(1$,

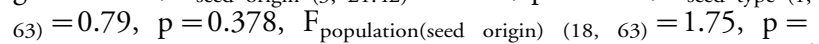
$0.054, \mathrm{~F}_{\text {seed }}$ origin $\times_{\text {seed type }(3,63)}=1.18, \mathrm{p}=0.323$; rate of germination, $\mathrm{F}_{\text {seed origin }(3,20.51)}=21.57, \mathrm{p}<0.001, \mathrm{~F}_{\text {seed type }}(1$,

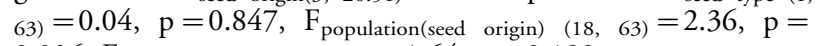
$0.006, \mathrm{~F}_{\text {seed origin }} \times_{\text {type }}(3,63)=1.64, \mathrm{p}=0.189$. 


\section{Trial 2. Origin and non-native populations}

In a second common garden experiment, we compared germination patterns among non-native populations from California and Argentina, and those growing under comparable contrasting climatic conditions of summer drought versus summer rain within the original range of C. solstitialis, southern Turkey and eastern Georgia, respectively (Fig. 1). We initiated this experiment in April 2005 using seeds collected in August 2004 (California, Turkey and Georgia) and January 2005 (Argentina), and the experiment included pappus and non-pappus seeds. Because of the constraints on collecting seeds in northern and southern hemispheres mentioned previously, for this experiment collections were made earlier in California than in Argentina, which reversed the timing of collections in our previous growth chamber experiment. This was intended to allow us to determine if differences in collection times consistently affected the outcome of our comparisons (Baskin and Baskin 2001). Seeds were germinated in nine$\mathrm{cm}$ diameter petri dishes, each containing three filter papers and $10 \mathrm{ml}$ of distilled water. In this experiment, each seed in petri dishes came from a different individual parent plant. These dishes were watered as needed throughout the experiment. The number of seeds, their distribution in the petri dishes, germination variables, and the test of viability were the same as in our first experiment. Germination was assessed daily for a week and then at larger intervals for a total of 30 days (Fig. 2B).

\section{Trial 3. Maternal effects}

Because early life-history traits are likely to be influenced by maternal effects (Rossiter 1996), we assessed this possibility using seeds from the 12 populations sampled in California and Argentina in 2002, five populations sampled in Turkey in 2004, and five populations sampled in Georgia also in 2004 (Supplementary material Appendix 1). Five plants from each population were grown from seeds in common conditions in a greenhouse (see Hierro et al. 2006 p. 147 for details on the methods). Once plants flowered, we crosspollinated all inflorescences produced by the five individuals within a population with a brush every 1-2 days until flowers senesced. Each population was separated by at least $1.5 \mathrm{~m}$ within the greenhouse from each other populations and inflorescences were bagged to avoid pollination among populations. At senescence (after $\sim$ eight months of growth), plants and seeds were harvested. The biomass and number of inflorescences for individual plants were similar among populations from all regions (Hierro et al. 2006). Two months after collection, we used these seeds to conduct a third germination experiment in the growth chamber under the same conditions described for the previous experiment. Because the number of seeds obtained from plants grown in the greenhouse was limited, we used a minimum of 10 and a maximum of 30 pappus seeds and the same number of non-pappus seeds for each population. Because of variation in available seed number, seeds from each population were germinated in one to three petri dishes, each containing 10 seeds. Intervals of germination assessment, response variables, and viability test were as in the previous trial.

\section{Trial 4. Native and non-native populations}

In a final experiment, we substantially increased our sampling area in native ranges, and studied the germination patterns of $C$. solstitialis populations experiencing either summer drought $(n=16)$ or summer rain $(n=13)$ in Europe, Turkey and the Caucasus (Fig. 1). We also included ten non-native populations, five from California and five from central Argentina. This experiment was started in January 2007 with seeds obtained in the August 2006 collection for native populations, the August 2004 collection for Californian populations, and the January 2005 collection for the Argentinean populations. Nonnative populations included in this common garden experiment were the five populations that were the farthest apart from each other geographically in the 2004 and the 2005 collection conducted in California and Argentina, respectively. Germination conditions, the number of seeds, their distribution in petri dishes, intervals of germination assessment, variables, and test of viability were as described in Trial 2.

\section{Effects of environmental quality and risk}

The proportion of seed germination for a species or population has been linked to specific characteristics of environmental quality and risk, which are commonly based on the total amount of precipitation and the inter-annual variation of precipitation occurring in the distributional range of the species or population (Philippi 1993, Clauss and Venable 2000, Venable 2007). In order to examine this relationship for $C$. solstitialis, we calculated several precipitation variables for a number of localities near our seed collection sites (Fig. 1, Table 1) from data obtained from local meteorological stations and correlated these variables with germination fractions recorded in the germination experiments. We determined the following measures: 1) average annual precipitation, which has been cited as a general measure of environmental quality (Philippi 1993); 2) total mean precipitation occurring from December through February and from June through August for localities in northern and southern hemispheres, respectively, as the amount of precipitation that occurs after the germination of $C$. solstitialis (i.e. winter precipitation) may be a crucial factor selecting for delayed germination (Clauss and Venable 2000, Venable 2007); 3) probability of occurrence of 'good years' and 'good winters', which we determined as the fraction of years or winters with precipitation equal to or greater than the mean, and 4) coefficient of variation (CV) of annual and winter precipitation (Philippi 1993, Clauss and Venable 2000).

\section{Statistical analyses}

Germination data were analyzed with nested ANOVA. In our first experiment, which involved only pappus seeds, the cumulative percent germination at the end of the experiment and the rate of germination between non-native populations were compared with two-way ANOVA, where seed origin was considered as a fixed factor and population as a random factor nested within seed origin. Rate of germination was transformed with the arcsine function to 
Table 1. Measures of environmental quality and risk for representative localities throughout sampled regions. CV $=$ coefficient of variation; $p_{g-y}=$ probability of good years; $p_{g-w}=$ probability of good winters.

\begin{tabular}{|c|c|c|c|c|c|c|}
\hline Locality & $\begin{array}{l}\text { Precipitation } \\
\text { regime }\end{array}$ & Coordinates & $\begin{array}{l}\text { Annual precipitation } \\
\text { mean }(\mathrm{mm}) \text { and } \mathrm{CV}\end{array}$ & $\begin{array}{l}\text { Winter precipitation } \\
\text { mean }(\mathrm{mm}) \text { and } \mathrm{CV}\end{array}$ & $p_{g-y}$ & $p_{g-w}$ \\
\hline Davis, California & summer drought & $38^{\circ} 31^{\prime} \mathrm{N}, 121^{\circ} 46^{\prime} \mathrm{W}$ & 482 and $32(1983-2006)$ & 270 and 44 & 0.38 & 0.48 \\
\hline Villares del Saz, Spain & summer drought & $39^{\circ} 50^{\prime} \mathrm{N}, 2^{\circ} 30^{\prime} \mathrm{W}$ & 529 and 29 (1956-2006) & 154 and 56 & 0.52 & 0.43 \\
\hline Montpellier, France & summer drought & $43^{\circ} 38^{\prime} \mathrm{N}, 3^{\circ} 51^{\prime} \mathrm{E}$ & 646 and 36 (1998-2007) & 152 and 66 & 0.40 & 0.44 \\
\hline Heraklion, Crete & summer drought & $35^{\circ} 16^{\prime} \mathrm{N}, 25^{\circ} 07^{\prime} \mathrm{E}$ & 480 and 25 (1947-2006) & 245 and 34 & 0.52 & 0.49 \\
\hline Aydin, Turkey & summer drought & $37^{\circ} 50^{\prime} \mathrm{N}, 27^{\circ} 51^{\prime} \mathrm{E}$ & 615 and 24 (1971-2006) & 287 and 39 & 0.53 & 0.44 \\
\hline Yerevan, Armenia & summer drought & $40^{\circ} 09^{\prime} \mathrm{N}, 44^{\circ} 30^{\prime} \mathrm{E}$ & 295 and 25 (1924-2005) & 71 and 38 & 0.44 & 0.47 \\
\hline Santa Rosa, Argentina & summer rain & $36^{\circ} 37^{\prime} \mathrm{S}, 64^{\circ} 17^{\prime} \mathrm{W}$ & 638 and $30(1911-2006)$ & 59 and 78 & 0.45 & 0.38 \\
\hline Debrecen, Hungary & summer rain & $47^{\circ} 29^{\prime} \mathrm{N}, 21^{\circ} 37^{\prime} \mathrm{E}$ & 568 and 21 (1901-2000) & 107 and 38 & 0.53 & 0.49 \\
\hline lasi, Romania & summer rain & $47^{\circ} 14^{\prime} \mathrm{N}, 27^{\circ} 20^{\prime} \mathrm{E}$ & 637 and 21 (1996-2006) & 97 and 44 & 0.55 & 0.58 \\
\hline Telavi, Georgia & summer rain & $41^{\circ} 55^{\prime} \mathrm{N}, 45^{\circ} 28^{\prime} \mathrm{E}$ & 767 and 18 (1940-1992) & 93 and 45 & 0.50 & 0.46 \\
\hline
\end{tabular}

meet ANOVA assumptions. Data from the three common garden experiments involving pappus and non-pappus seed types were analyzed with three-way ANOVA, where seed origin and type were included as fixed factors and population as a random factor nested within origin; posthoc comparisons were performed with Tukey tests. We applied arcsine transformation to cumulative percent germination in all three of these experiments.

We explored the association between mean cumulative percent germination of $C$. solstitialis populations and the metrics of environmental quality and risk in the regions where populations were collected with Pearson correlation (Phillipi 1993, Clauss and Venable 2000, Venable 2007). Because the direction of the association was known in advance, we conducted analyses with one-tailed probabilities (SPSS ver. 13.0 2004). For native populations, we used germination fractions obtained in Trial 4 (Armenia $=$ five populations, Crete $=$ two, France $=$ one, Georgia $=$ five, Hungary $=$ three, Romania $=$ five, Spain $=$ three, Turkey = five; Fig. 1). For non-native populations, we used germination fractions obtained in Trial 2 because the sample size of both Californian $(\mathrm{n}=14)$ and Argentinean $(\mathrm{n}=14)$ populations in this common garden was the largest among experiments conducted here.

\section{Results}

\section{Common garden experiments}

\section{Trial 1}

The proportion of viable pappus seeds that germinated from the non-native region with summer drought, California, was nearly two and a half times larger than that of pappus seeds from the non-native region with summer rain, central Argentina (Fig. 2A). Similarly, germination rates were much higher in pappus seeds from California than in pappus seeds from Argentina (Timson's index: 856.53土 $269.50[1 \mathrm{SD}]$ vs $300.29 \pm 107.71)$.

\section{Trial 2}

Pappus and non-pappus seeds from Turkey (original range, summer drought), Georgia (original range, summer rain), and California germinated at similar numbers and rates (post-hoc comparison, $\mathrm{p}>0.05$; Fig. 2B; Timson's index, pappus, 1070.47 $\pm 191.64, \quad 1133.72$ \pm 125.00 , and $1181.50 \pm 168.71$; non-pappus, 1116.84 $\pm 177.14,1224.92 \pm 59.89$, and $1156 \pm 206.19$ for Turkey, Georgia and California, respectively), whereas seeds from central Argentina exhibited the smallest proportions of germinating seeds and the slowest rates of germination (post-hoc comparison, $\mathrm{p}<0.05$; Timson's index, pappus $734.87 \pm 232.18$; non-pappus, $447.30 \pm 237.14)$. In addition, the percent germination and germination rate of pappus seeds were higher than those of non-pappus seeds in Argentinean genotypes (post-hoc comparison, p <0.05). Final germination fractions and rates of germination of Californian and Argentinean seeds were higher here than in our previous experiment. These differences may have been due to variation between experiments in preparing petri dishes, adding water, sample sizes, and/or sampling year (Clauss and Venable 2000).

\section{Trial 3}

Again, we found no differences in germination percentages and rates for seeds from Turkey, Georgia and California (post-hoc comparison, $\mathrm{p}>0.05$; Fig. 2C; Timson's index, pappus, $1229.43 \pm 133.23,1107.44 \pm 288.96$, and $1060.07 \pm 262.05$; non-pappus, $1191.88 \pm 126.53$, $1228.52 \pm 199.90$, and $1106.44 \pm 239.13$ for Turkey, Georgia and California, respectively), and reduced germination proportions and rates for seeds from Argentina (post-hoc comparison, $\mathrm{p}<0.05$ ). Unlike our previous experiment, however, we did not detect significant differences in germination between seed morphs from Argentina (post-hoc comparison, $\mathrm{p}>0.05$; Timson's index, pappus, $555.25 \pm 373.53$; non-pappus, $324.79 \pm 274.54)$. This inconsistent outcome may have been due to a smaller sample size here than in the previous experiment. Importantly, this common garden experiment confirms that germination responses of Turkish, Georgian, Californian and Argentinean populations have a genetic basis. In addition, since percent germination and Timson's indices were higher for $\mathrm{F}_{1} \mathrm{~s}$ than for mothers in non-native populations (Fig. 2A, 2C), maternal effects could have also contributed to the germination patterns of Californian and Argentinean genotypes; however, germination on mothers and $\mathrm{F}_{1} s$ was assessed slightly differently in terms of petri dish preparation and water addition, which may have additionally influenced experimental outcomes. Germination values of Turkish and Georgian populations, on the other hand, were strikingly similar between $\mathrm{F}_{1} \mathrm{~s}$ and maternal plants (Fig. 2B, 2C). 


\section{Trial 4}

As in previous experiments, final germination proportions and germination rates were similar among seeds from native and Californian populations (Fig. 3; post-hoc comparisons, $\mathrm{p}>0.05$; Timson's index: pappus, 954.39 \pm 280.10 , $1058.67 \pm 173.65$, and $918.10 \pm 145.44$; non-pappus, $1030,54 \pm 257.76, \quad 1104.78 \pm 181.11, \quad$ and $930.74 \pm$ 183.55 for native summer drought, native summer rain, and California, respectively), but percentages and rates were significantly lower for seeds from central Argentina (post-hoc comparisons, $\mathrm{p}<0.05)$. Unexpectedly, germination responses of pappus and non-pappus seeds from Argentina were highly comparable (post-hoc comparisons, $\mathrm{p}>0.05$ for both germination fractions and rates; Timson's index: pappus, 690.29 \pm 271.00 ; non-pappus, $682.27 \pm 300.59)$. Germination proportions and rates of Turkish and Georgian populations were similar to those obtained in our previous experiments (germination proportions: pappus, 96.13 \pm 2.60 and $92.62 \pm 6.34$; non-pappus, $96.34 \pm 2.37$ and $94.88 \pm 7.23$, Timson's index: pappus, 987.12 \pm 91.72 and 1069.28 \pm 127.27 ; non-pappus, $1078.59 \pm 113.19$ and $1124.61 \pm 161.22$, for Turkey and Georgia, respectively).

\section{Effects of environmental quality and risk}

We detected a strong association between germination fractions and risk during the winter, such that germination percentages of pappus and non-pappus seeds tended to be lower in both native and non-native populations experiencing greater coefficients of variation of winter precipitation and lower probabilities of good winters (Fig. 4, Table 1).

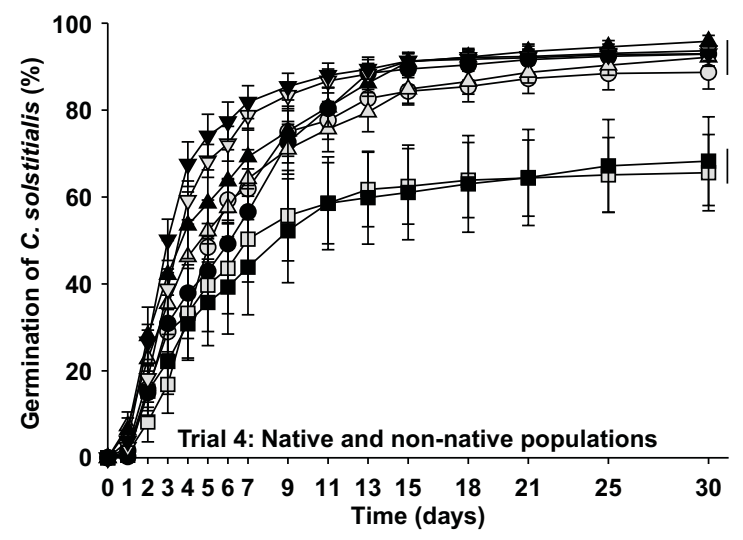

Figure 3. Germination of C. solstitialis pappus (gray symbols) and non-pappus (black symbols) seeds from populations experiencing summer drought and summer rain climates within native and non-native ranges. Symbols are means \pm 1 SE of 16 summer drought (triangles up) and 13 summer rain (triangles down) native populations, five non-native populations from California (circles), and five from central Argentina (squares). Non-native populations are a subsample of those used in Fig. 2B. Lines next to germination curves separate statistically different final cumulative germinations $(\mathrm{p}<0.05)$. Cumulative germination, $\mathrm{F}_{\text {seed origin (3, }}$ $35)=13.06, \quad \mathrm{p}<0.001, \mathrm{~F}_{\text {seed }}$ type $(1,191)=6.01, \mathrm{p}=0.015$, $\mathrm{F}_{\text {population(seed origin) }(35,191)}=4.65, \mathrm{p}<0.001, \mathrm{~F}_{\text {seed origin }} \times_{\text {seed }}$ type $(3,191)=2.27, \mathrm{p}=0.081$; rate of germination, $\mathrm{F}_{\text {seed origin }(3 \text {, }}$ $35)=4.67, \mathrm{p}=0.008, \mathrm{~F}_{\text {seed type }(1,191)}=2.42, \mathrm{p}=0.122, \mathrm{~F}_{\text {popu- }}$ lation(seed origin) $(35,191)=13.47, \mathrm{p}<0.001, \mathrm{~F}_{\text {seed origin }} \times_{\text {seed type }(1,}$ 191) $=0.94, \mathrm{p}=0.425$.

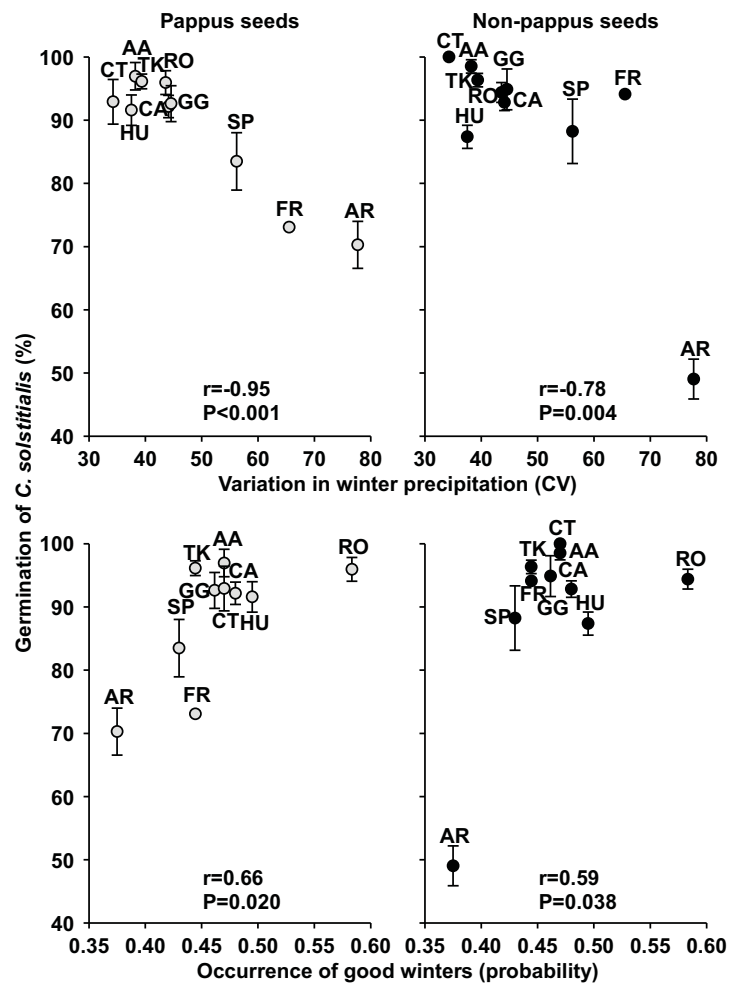

Figure 4. Mean cumulative germination percentages ( \pm 1 SE) of pappus and non-pappus seeds of $C$. solstitialis populations plotted against the coefficient of variation $(\mathrm{CV})$ of winter precipitation and the probability of occurring a good winter. $\mathrm{AA}=$ Armenia, $\mathrm{AR}=$ Argentina,$\quad \mathrm{CA}=$ California,$\quad \mathrm{CT}=$ Crete,$\quad \mathrm{FR}=$ France, $\mathrm{GG}=$ Georgia, $\mathrm{HU}=$ Hungary, $\mathrm{RO}=$ Romania, $\mathrm{SP}=$ Spain, $\mathrm{TK}=$ Turkey.

In addition, the proportion of germinating pappus seeds was correlated with variation in annual precipitation $(\mathrm{r}=-0.68, \mathrm{p}=0.015)$, but not with the probability of good years $(r=0.41, p=0.120)$. Germination fractions of non-pappus seeds, on the other hand, were not correlated with any of the measures of annual risk ( $\mathrm{CV}$ annual precipitation, $\mathrm{r}=-0.28, \mathrm{p}=0.220$; probability of good years, $r=0.15, p=0.345$ ). In contrast to surrogates for risk, mean cumulative germination percentages were not associated with any of the measures describing environmental quality (pappus and non-pappus seeds vs mean annual precipitation: $\mathrm{r}=-0.32, \mathrm{p}=0.183$ and $\mathrm{r}=-0.25, \mathrm{p}=$ 0.239 , respectively; pappus and non-pappus seeds vs winter precipitation: $\mathrm{r}=0.28, \mathrm{p}=0.216$ and $\mathrm{r}=0.43, \mathrm{p}=0.109$, respectively). Except for the correlation between probability of good winters and the coefficient of variation of annual precipitation $(\mathrm{r}=-0.47, \mathrm{p}=0.085)$, precipitation variables for which we found significant associations with percent germination were correlated with each other (coefficient of variation of winter precipitation vs probability of good winters: $r=-0.63, p=0.024$; coefficient of variation of winter precipitation vs coefficient of variation of annual precipitation: $\mathrm{r}=0.62, \mathrm{p}=0.028$ ).

Correlations of germination percentages and precipitation variables were strongly influenced by a single region, central Argentina, particularly for non-pappus seeds (Fig. 4). Consequently, we performed additional correlations without including this region in the analyses. Germination fractions 
of pappus seeds maintained a strong association with variation in winter precipitation $(\mathrm{r}=-0.91$, $\mathrm{p}<0.001$ ), but this relationship did not hold for nonpappus seeds $(\mathrm{r}=-0.36, \mathrm{p}=0.172)$. In addition, germination of both pappus and non-pappus seeds were no longer correlated with the probability of good winters $(r=0.44$, $\mathrm{p}=0.117$ and $\mathrm{r}=0.11, \mathrm{p}=0.387$, respectively). Without Argentina, the association between germination proportions of pappus seeds and variation in annual precipitation improved slightly $(r=-0.70, p=0.017)$, whereas the correlation of these proportions with the probability of good years remained non-significant $(r=0.39, p=0.150)$. Finally, as before, germination fractions of non-pappus seeds were not correlated with any of the measures of annual risk, and germination percentages of both seed morphs were not associated with any of the measures describing environmental quality ( $\mathrm{p}>0.250$ in all cases).

In contrast to native populations, for which we found generally consistent germination proportions in the different experiments conducted in this study, the percent germination of non-native populations differed among experiments. For this reason, we also conducted correlations using final germination proportions of Californian and Argentinean genotypes resulting from Trial 1, Trial 3 and Trial 4. Importantly, the outcomes of these correlations were comparable to those reported here (Supplementary material Appendix 2).

\section{Discussion}

Local genetic differentiation of populations has been demonstrated for a number of native plant species (reviewed by Linhart and Grant 1996). More recently, the exploration of mechanisms underlying non-native plant invasions has shown that such differentiation also occurs between native and non-native conspecifics (Bossdorf et al. 2005). Furthermore, genetic differentiation has also been detected among plant populations within their non-native range (Naylor 1983, Wu et al. 1987, Lacey 1988, Weber and Schmid 1998, Neuffer and Hurka 1999, Meyer and Allen 1999). The next step, studying how variation among plant populations in the non-native range compares to variation among populations in the native range, has been undertaken in only three investigations (Maron et al. 2004, 2007, Leger and Rice 2007). Similar to the work pioneered by Huey et al. (2000) for Drosophila subobscura, both Maron et al. (2004, 2007) and Leger and Rice (2007) found convergent geographic clines in populations from the native and non-native range of Hypericum perforatum and Eschscholzia californica, respectively. Clines in these studies corresponded to variation in general climatic patterns, such as changes in climate between northern and southern latitudes (Maron et al. 2004, 2007) or between coastal versus inland environments (Leger and Rice 2007). In contrast to these results, our comparisons based on general climatic patterns (i.e. summer drought vs summer rain) did not detect parallel clines in germination traits for populations from native and non-native ranges, as all native populations, irrespective of the climate in which they occurred, and non-native populations from the region with a summer-drought climate displayed similarly high germination proportions and rates; whereas non-native genotypes from the region with a summer rain regime exhibited much lower germination fractions and rates (Fig. 2, 3). On the other hand, our comparisons based on precipitation variables, which are commonly used as surrogates for environmental quality and risk, showed that for the most abundant seed morph, seeds with a pappus, germination responses of populations in both native and non-native ranges correlated strongly with 'risk' experienced during the winter. Specifically, and as predicted by bethedging theory, germination fractions of pappus seeds were lower in native and non-native populations experiencing greater inter-annual variation in winter precipitation (Fig. 4). For non-pappus seeds, however, this correlation was greatly influenced by non-native genotypes from central Argentina, which are from the region with the highest variation in winter precipitation of all the studied regions (Table 1) and exhibited the lowest proportions of germinating seeds in all our experiments (Fig. 2-4); after removing central Argentina from analyses, there was no association between germination fractions of non-pappus seeds and winter precipitation variation. Similarly, germination fractions of both pappus and non-pappus seeds correlated with probability of occurrence of good winters only in the presence of Argentinean variables. Overall, these findings suggest that rather than general climatic patterns, the degree of risk experienced at early developmental stages could exert an important control over the germination strategy of C. solstitialis populations in both native and non-native ranges. In addition, they reveal the largely unique nature among studied populations of seed germination in nonnative genotypes from central Argentina.

Germination fractions of pappus seeds were also correlated with variation in annual precipitation, suggesting that overall annual risk could also play a role in the germination behavior of $C$. solstitialis populations. Interestingly, however, annual precipitation variation can not explain the genetic differentiation detected consistently throughout our experiments between non-native genotypes from California and Argentina, as the coefficient of variation of annual precipitation is slightly higher in northern California than in central Argentina (Table 1). In addition, Pearson's coefficient improved after dropping Argentina from these correlations. Perhaps, extreme levels of uncertainty during the months following germination have a stronger influence on Argentinean genotypes than variation in total annual precipitation.

According to our literature search, no previous study has investigated variation in seed germination among conspecific populations at the geographical scale employed here. For pappus seeds, linking the degree of expression of a putative bet-hedging trait, proportion of dormant seeds, with the magnitude of a surrogate for risk, variation in winter precipitation, across a range of risk levels, provides an initial indication that such variation could have selected for bet-hedging across the distributional range of C. solstitialis (Venable 2007). Indeed, populations experiencing comparable variation in winter precipitation in the native and non-native range tended to display similar germination fractions for this seed type (Fig. 4). In contrast, for non-pappus seeds the link between degree of dormancy and level of winter risk does not hold when outlier 
Argentinean variables are removed from analyses, providing weaker support for bet-hedging across $C$. solstitialis populations. Demonstrating bet-hedging empirically is remarkably challenging (Venable 2007), and in our study system it warrants additional inquiries, including increasing sample size in regions with high variation in winter precipitation and in the non-native range to add populations from Chile, South Africa and Australia, measuring germination fractions in situ, conducting field common gardens with the progeny of plants previously grown under similar conditions, establishing a causal association among environmental variation, fitness, and seed dormancy through the collection of long-term demographic information, and determining the origin of non-native populations through genetic analyses.

As for dormancy, seed heteromorphism is considered to be a characteristic trait of the bet-hedging strategy in annual plants (Venable 1985). Seed morphs of C. solstitialis are known to differ in dispersal time (Maddox et al. 1996). In our study, the germination responses of seeds from southern France and central Argentina suggest that pappus and nonpappus seeds may also differ in germination fractions and rates in environments with high variation in winter precipitation (Fig. 2, 4, Table 1), which is in line with the idea that environmental risk could have selected for bethedging in $C$. solstitialis populations. These germination responses, however, require further investigation as divergence between Argentinean seed types was not uniform across common gardens, and French genotypes lacked replication.

Although the germination responses of non-native C. solstitialis populations varied among experiments, our results are remarkably consistent in that Argentinean genotypes, which experience much higher levels of variation in winter precipitation than Californian genotypes (Table 1), displayed higher proportions of dormant seeds and lower germination rates than Californian populations in all common garden experiments (Fig. 2, 3). Importantly, this germination pattern was maintained after mitigating for potential non-genetic effects conferred by the parental environment (Fig. 2C), which strongly indicates that it is genetically-based. Attempts to control for maternal effects are notably absent in most comparisons of native versus non-native populations. In fact, in reviewing the subject, Bossdorf and colleagues (2005) report only one case where such attempts were conducted (van Kleunen and Schmid 2003); since then, we have found only one additional example (Lavergne and Molofsky 2007).

Several mechanisms could be responsible for the genetic differentiation in germination traits of Californian versus Argentinean populations, including coincidental introductions, genetic drift, and natural selection operating on phenotypes formed by either a novel combination of genes (Ellstrand and Schierenbeck 2000) or pre-adapted genotypes (i.e. the sorting-out hypothesis - Müller-Schärer and Steinger 2004; see Leger and Rice 2007 for a comprehensive discussion on these mechanisms). Outcrossing plants partition most of their genetic diversity within, rather than among, populations, which increases the probability of possessing high genetic variation upon introduction because even a few immigrants can carry much of the species' genetic variation (Novak and Mack 2005). Consequently, a largely outcrossing floral biology (Sun and Ritland 1998) added to a history of multiple accidental introductions from a broad collection of native populations (Hijano and Basigalup 1995, Gerlach 1997) suggest that C. solstitialis populations could have possessed enough genetic variation to respond to local environmental conditions. Because the time needed for the manifestation of beneficial mutations in natural populations (Dobzhansky 1970) is presumably longer than the time provided by human-assisted introductions, such a response is more likely to have occurred through novel combinations of genes resulting from gene exchange between previously distant populations (Ellstrand and Schierenbeck 2000) or differential survival and establishment of introduced genotypes (Müller-Schärer and Steinger 2004). In a hypothetical sorting-out scenario, genotypes with large, medium and small proportions of germinating seeds have been introduced into both California and central Argentina, but whereas only genotypes with relatively large germination proportions have survived and established in California, only those with small germination proportions have survived and established in central Argentina. Critical exploration of this, as well as other mechanisms potentially involved in the germination pattern reported here, awaits, however, the assistance of molecular genetic information (Maron et al. 2004). In spite of this limitation, our work raises the possibility that rapid adaptive changes in germination strategies may contribute to the success of globally distributed invaders.

Acknowledgements - We thank C. Hall, T. Bassett, N. Wegman, Y. Shimizo, K. Asakawa, K. Evans, M. Reedy and L. Greenwood for lab and field assistance; T. Widmer and F. Guernache for seeds; G. Vergara, N. Karatarakis and Météo-France for precipitation data; M. González-Roglich for Fig. 1, and J. Maron, A. Sala, A. Valiente-Banuet and C. Lortie for comments. We also thank US Dept of Defense SERDP, Rocky Mountain Research Station, The Aldo Leopold Wilderness Center, NSF DDIG and International Programs, USDA, The Sponsored Research Office of the Univ. of Montana, the Civilian Research Development Foundation, and TUBITAK for financial support.

\section{References}

Barrett, S. C. H. and Husband, B. C. 1990. Genetics of plant migration and colonization. - In: Brown, A. H. D. et al. (eds), Plant population genetics, breeding, and genetic resources. Sinauer, pp. 254-277.

Baskin, C. C. and Baskin, J. M. 2001. Seeds: ecology, biogeography and evolution of dormancy and germination. - Academic Press.

Benefield, C. B. et al. 2001. Reproductive biology of yellow starthistle: maximizing late-season control. - Weed Sci. 49: 83-90.

Bossdorf, O. et al. 2005. Phenotypic and genetic differentiation between native and introduced plant populations. - Oecologia 144: $1-11$.

Clausen, J. et al. 1941. Regional differentiation in plant species. - Am. Nat. 75: 231-250.

Clauss, M. J. and Venable, D. L. 2000. Seed germination in desert annuals: an empirical test of adaptive bet hedging. - Am. Nat. 155: $168-186$.

Cohen, D. 1966. Optimizing reproduction in a randomly varying environment. - J. Theor. Biol. 12: 119-129. 
Cottrell, H. J. 1947. Tetrazolium salt as a seed germination indicator. - Nature 159: 748.

Dobzhansky, T. 1970. Genetics of the evolutionary process. - Columbia Univ. Press.

Donohue, K. et al. 2005. The evolutionary ecology of seed germination of Arabidopsis thaliana: variable natural selection on germination timing. - Evolution 59: 758-770.

Ellstrand, N. C. and Schierenbeck, K. A. 2000. Hybridization as a stimulus for the evolution of invasiveness in plants? - Proc. Natl Acad. Sci. USA 97: 7043-7050.

Evans, A. S. and Cabin, R. J. 1995. Can dormancy affect the evolution of post-germination traits? The case of Lesquerella fendleri. - Ecology 76: 344-356.

Gerlach, J. D. 1997. How the west was lost: reconstructing the invasion dynamics of yellow starthistle and other plant invaders of western rangelands and natural areas. - Proc. Calif. Exotic Pest Plant Council Symp. 3: 67-72.

Hierro, J. L. et al. 2006. Disturbance facilitates invasions: the effects are stronger abroad than at home. - Am. Nat. 168: $144-156$.

Hijano, E. and Basigalup, D. 1995. El cultivo de la alfalfa en la República Argentina. - In: Hijano, E. and Navarro, A. (eds), La Alfalfa en la Argentina. Inst. Nacional Tecnol. Agropecuaria, Buenos Aires, Argentina, pp. 13-18, in Spanish.

Huey, R. B. et al. 2000. Rapid evolution of a geographic cline in size in an introduced fly. - Science 287: 308-309.

Joley, D. B. et al. 1992. Dynamics of yellow starthistle (Centaurea solstitialis) achenes in field and laboratory. - Weed Sci. 40: 190-194.

Joley, D. B. et al. 1997. Effect of light and temperature on germination of dimorphic achenes of Centaurea solstitialis in California. - Can. J. Bot. 75: 2131-2139.

Joley, D. B. et al. 2003. Parameters affecting germinability and seed bank dynamics in dimorphic achenes of Centaurea solstitialis in California. - Can. J. Bot. 81: 993-1007.

Koskinen, M. T. et al. 2002. Contemporary fisherian life-history evolution in small salmonid populations. - Nature 419: 826830.

Lacey, E. P. 1988. Latitudinal variation in reproductive timing of a short-lived monocarp, Daucus carota (Apiaceae). - Ecology 69: 220-232.

Lavergne, S. and Molofsky, J. 2007. Increased genetic variation and evolutionary potential drive the success of an invasive grass. - Proc. Natl Acad. Sci. 104: 3883-3888.

Leger, E. A. and Rice, K. J. 2007. Assessing the speed and predictability of local adaptation in invasive California poppies (Eschscholzia californica). - J. Evol. Biol. 20: 1090-1103.

Linhart, Y. B. and Grant, M. C. 1996. Evolutionary significance of local genetic differentiation in plants. - Annu. Rev. Ecol. Syst. 27: 237-277.

Maddox, D. M. et al. 1985. Distribution of yellow starthistle (Centaurea solstitialis) and Russian knapweed (Centaurea repens). - Weed Sci. 33: 315-327.

Maddox, D. M. et al. 1996. Pollination biology of yellow starthistle (Centaurea solstitialis) in California. - Can. J. Bot. 74: 262-267.

Maron, J. L. et al. 2004. Rapid evolution of an invasive plant. - Ecol. Monogr. 74: 261-280.

Maron, J. L. et al. 2007. Contrasting plant physiological adaptation to climate in the native and introduced range of Hypericum perforatum. - Evolution 61: 1912-1924.

Meyer, S. E. and Allen, P. S. 1999. Ecological genetics of seed germination regulation in Bromus tectorum L. - Oecologia 120: $27-34$.

Müller-Schärer, H and Steinger, T. 2004. Predicting evolutionary change in invasive, exotic plants and its consequences for plant-herbivore interactions. - In: Ehler, L. E. et al. (eds), Genetics, evolution and biological control. CABI, pp. 137162.

Naylor, J. M. 1983. Studies on the genetic control of some physiological processes in seeds. - Can. J. Bot. 61: 3561-3567.

Neuffer, B. and Hurka, H. 1999. Colonization history and introduction dynamics of Capsella bursa-pastoris (Brassicaceae) in North America: isozymes and quantitative traits. - Mol. Ecol. 8: 1667-1681.

Novak, S. J. and Mack, R. N. 2005. Genetic bottlenecks in alien plant species: influence of mating systems and introduction dynamics. - In: Sax, D. F. et al. (eds), Species invasions: insights into ecology, evolution and biogeography. Sinauer, pp. 341-363.

Philippi, T. 1993. Bet-hedging germination of desert annuals: variation among populations and maternal effects in Lepidium lasiocarpum. - Am. Nat. 142: 488-507.

Prodan, I. 1930. Centaurelle Romaniei. - Buletinul Academiei de Inalte Studii Agronomice Cluj-Roumanie Institutul de Arte Grafice "Ardealul" Strada Memorandului No. 22, in German and Romanian.

Rossiter, M. C. 1996. Incidence and consequences of inherited environmental effects. - Annu. Rev. Ecol. Syst. 27: 451-476.

Sax, D. F. et al. 2007. Ecological and evolutionary insights from species invasions. - Trends Ecol. Evol. 22: 465-471.

Sheley, R. L. and Larson, L. L. 1994. Observation: comparative life history of cheatgrass and yellow starthistle. - J. Range Manage. 47: 450-456.

Sun, M. and Ritland, K. 1998. Mating system of yellow starthistle (Centaurea solstitialis), a successful colonizer in North America. - Heredity 80: 225-232.

Timson, J. 1965. New method of recording germination data. - Nature 207: 216-217.

Turesson, G. 1922. The genotypical response of the plant species to the habitat. - Hereditas 3: 211-350.

van Kleunen, M. and Schmid, B. 2003. No evidence for an evolutionary increased in competitive ability (EICA) in an invasive plant. - Ecology 84: 2816-2823.

Venable, D. L. 1985. The evolutionary ecology of seed heteromorphism. - Am. Nat. 126: 577-595.

Venable, D. L. 2007. Bet heding in a guild of desert annuals. - Ecology 88: 1086-1090.

Venable, D. L. and Brown, J. S. 1988. The selective interactions of dispersal, dormancy, and seed size as adaptations for reducing risk in variable environments. - Am. Nat. 131: 360-384.

Uygur, S. et al. 2004. Population densities of yellow starthistle (Centaurea solstitialis) in Turkey. - Weed Sci. 52: 746-753.

Wagenitz, C. 1955. Pollenmorphologie and Systematik in der gattung Centaurea L. S. I. - Flora 142: 213-275, in German.

Weber, E. and Schmid, B. 1998. Latitudinal population differentiation in two species of Solidago (Asteraceae) introduced into Europe. - Am. J. Bot. 85: 1110-1121.

Wu, K. K. et al. 1987. Genetic differentiation in temperatureenforced seed dormancy among golf course populations of Poa annua L. - New Phytol. 107: 623-631.

Supplementary material (available online as Appendix O17283 at $<$ www.oikos.ekol.lu.se/appendix $>$ ). Appendix 1. Table A1. Location, elevation and final cumulative germination of Centaurea solstitialis populations used in this study. Appendix 2. Table B1. Results of correlation analyses conducted with germination proportions obtained in Trial 4 for native populations and Trial 1, Trial 3 and Trial 4 for non-native populations. 